\title{
EMBRAPA: reestruturando-se para ampliar sua contribuição para a inovação no setor agropecuário brasileiro
}

\author{
EMBRAPA: reestructuring to increase its contribution to innovation in the \\ brazilian agricultural sector
}

\author{
Luís Carlos Stutz ${ }^{1}$ \\ Marcelo Farid Pereira ${ }^{2}$ \\ ${ }^{1}$ Embrapa Soja, Distrito de Warta, PR, Brasil \\ ${ }^{2}$ Universidade Estadual de Maringá, Maringá, PR, Brasil
}

\begin{abstract}
Resumo
Países nos quais governo, empresas e instituições de pesquisa tratam a inovação como prioridade têm experimentado níveis expressivos de desenvolvimento econômico. A Embrapa foi criada com a missão de viabilizar o crescimento da agropecuária brasileira por meio da pesquisa e da inovação, transformando os conhecimentos gerados em tecnologias para o produtor rural. Os resultados da produção agrícola nacional demonstram o cumprimento de sua função, mas a empresa precisa se amoldar à nova realidade em que são exigidos processos contínuos de inovação. O presente trabalho foi desenvolvido com objetivo de demonstrar o que a empresa tem feito para a manutenção de sua relevância para o Brasil. A metodologia compreendeu uma revisão de literatura e a avaliação de documentos. Como resultado, verificou-se que a empresa está implantando um Macroprocesso de Inovação, que reestruturou seu processo de pesquisa para fortalecer as fases de transferência de tecnologias, de monitoramento e de avaliação de seus impactos.
\end{abstract}

Palavras-chave: Inovação. Transferência de Tecnologia. Núcleo de Inovação Tecnológica.

\begin{abstract}
Countries where the government, companies and research institutions treat innovation as a priority have experienced significant levels of economic development. Embrapa was created with the mission of improving the growth of Brazilian agriculture through research and innovation, transforming knowledge into technologies for the farmers. The results of national agricultural production demonstrate the fulfillment of its function, but the company needs to face the new reality in which continuous innovation processes are required. The present study was developed to demonstrate what the company has been doing to keep its relevance to Brazil. The methodology comprised a literature review and documentary evaluation. As a result it was found that the company is implementing an Innovation Macroprocess, which has restructured its research process by strengthening the technology transfer, monitoring and impact assessment.
\end{abstract}

Keywords: Innovation. Technology Transfer. Technological Innovation Center.

Área Tecnológica: Propriedade Intelectual. Inovação Tecnológica e Transferência de Tecnologia. 


\section{Introdução}

Na última década, a sociedade tem cobrado de forma muito enfática que as empresas públicas apresentem resultados que de alguma forma melhorem as condições de vida da população, não aceitando mais apenas resultados teóricos que, em última instância, nada acrescentam de prático ao seu dia a dia. Em resposta, o governo, ao mesmo tempo em que tem aprimorado o sistema legal dando mais agilidade às instituições públicas, implanta formas mais efetivas de avaliação de resultados. Por sua vez, as instituições, notadamente as Universidades e as Instituições de Ciência e Tecnologia (ICTs), têm procurado se ajustar a essa conjuntura para, cada vez mais, trazer resultados para a sociedade (para quem trabalha) e para o Estado (que a criou).

A Embrapa está ciente da dependência econômica que o país tem da agricultura e do que ela representa nesse contexto e, por isso, não está apenas vivendo dos muitos frutos gerados nas primeiras quatro décadas de sua existência, mas tem buscado fazer ajustes institucionais para permanecer como empresa de vanguarda que sempre foi e continuar a entregar à sociedade o valor que dela é esperado, mantendo a sua relevância e o impacto de suas ações junto à agropecuária brasileira. Segundo matéria publicada em seu site por ocasião do aniversário de 46 anos,

[...] o momento é de se reinventar, atuar não apenas para aumentar a produção científica e as entregas imediatas para a sociedade, mas também prospectar cenários e oportunidades que permitam ajudar a construir o futuro da agropecuária nacional. (EMBRAPA, 2019a)

De acordo com o Balanço Social da empresa (EMBRAPA, 2019b), entre 2003 e 2017, a Embrapa publicou 16.493 documentos, ocupando o $8^{\circ}$ lugar entre todas as instituições do país, sendo superada apenas por sete Universidades públicas. Não há dúvida de que a empresa tem uma produção científica de excelência, porém a empresa está ciente de que, embora extremamente importantes, se não forem transformados em pesquisa aplicada para a sociedade, esses números perdem parte de sua relevância. Ela precisa que os resultados de seus processos de pesquisa e desenvolvimento não gerem apenas conhecimento e publicações, mas que eles cheguem à etapa de transferência de tecnologia e se transformem em inovações. O resultado do trabalho da Embrapa deve agregar valor ao produto nacional e aumentar, assim, sua competitividade e, consequentemente, a renda de toda a cadeia envolvida no agronegócio brasileiro. Esse foi o objetivo maior para sua criação e continua como grande desafio para o sucesso da agricultura brasileira.

Assim, o principal objetivo deste trabalho foi avaliar em que medida a Embrapa tem feito alterações em suas estruturas institucionais ligadas à Pesquisa, Desenvolvimento e Inovação (PD\&I) buscando ampliar seus resultados e cumprir sua missão. $\mathrm{O}$ artigo aborda alguns conceitos sobre inovação e como o sistema legal brasileiro trata o tema; trabalham-se os conceitos gerais sobre habitats de inovação e, especificamente, sobre os Núcleos de Inovação Tecnológica (NITs); discorre-se sobre a Embrapa, seu NIT e, mais detalhadamente, sobre o Macroprocesso de Inovação que está em fase de implantação visando a ajustes necessários à estrutura da empresa para manutenção e ampliação de sua relevância para a agricultura brasileira; conclui-se este estudo apresentando alguns resultados do agronegócio nacional visando a demonstrar a importância que a Embrapa tem para a economia do país. 


\subsection{Inovação}

O desenvolvimento econômico pode ser verificado particularmente nos países que têm priorizado a inovação e, assim, a partir de economias mais fortes possibilitam melhores condições de vida para sua população. O Brasil enfrenta muitas dificuldades no campo econômico, o que se reflete diretamente na sociedade, replicando o que se observa na maioria dos países em desenvolvimento.

Apesar dessa situação, existe no Brasil um arcabouço legal bastante bem estruturado no que se refere à inovação e à propriedade intelectual (PI) em suas diversas formas. Exemplificativamente e conforme sua hierarquia jurídica, podem ser citadas a Constituição Federal, de 1988 (BRASIL, 1988), a Emenda Constitucional n. 85, de 2005 (que alterou dispositivos na CF para atualizar o tratamento das atividades de ciência, tecnologia e inovação) (BRASIL, 2005), Lei n. 9.279/1996 (Lei da Propriedade Industrial) (BRASIL, 1996), Lei n. 9.456/1997 (Proteção de Cultivares) (BRASIL, 1997), Lei n. 9.609/1998 (trata da propriedade intelectual de programa de computador) (BRASIL, 1998a), Lei n. 9.610/1998 (Direitos Autorais) (BRASIL, 1998b), Lei n. 10.973/2004 (Lei de Inovação) (BRASIL 2004), Lei n. 13.123/2015 (dispõe sobre o acesso ao patrimônio genético nacional) (BRASIL 2015), e Lei n. 13.243/2016 (novo marco legal da inovação) (BRASIL 2016).

O fato de ter um arcabouço legal bem estruturado não significa que o país possui as condições necessárias para transformar sua realidade. Um conjunto de fatores gera essa transformação. É preciso que a legislação esteja alinhada às políticas públicas e estas devem ser elaboradas dentro de uma visão de Estado que possibilite, a longo prazo e feitos os ajustes necessários, a mudança na sociedade, que passa pela incorporação do conceito de inovação como sua práxis. Santos (2011) afirma que o progresso tecnológico e o desenvolvimento econômico geram o desenvolvimento tecnológico, o que explica as ações de muitos governos ao investirem em ciência e tecnologia. Luz et al. (2014) ressaltam a importância do estabelecimento de políticas que incentivem a criação dos habitats de inovação como mecanismos de promoção de um círculo virtuoso de troca de conhecimento científico e tecnológico entre empresas e instituições de pesquisa visando ao desenvolvimento socioeconômico. Os autores defendem que o governo brasileiro tem trabalhado no sentido de criar políticas e incentivos à inovação.

Embora isso seja verdade, principalmente nessas duas últimas décadas, e o governo tenha buscado criar mecanismos para viabilizar o desenvolvimento econômico através de políticas públicas e leis, avaliando nossa legislação percebe-se um lapso temporal muito grande, o que em parte ajuda a explicar os passos lentos com que se move o desenvolvimento econômico de nosso país. Embora a Constituição Federal de 1988 já trouxesse em seu artigo 218 a previsão de que "[...] o Estado promoverá e incentivará o desenvolvimento científico, a pesquisa e a capacitação tecnológica [...]" (BRASIL, 1988, art. 218), é somente em 2004 (16 anos, portanto, depois da $\mathrm{CF}$ ) que a Lei de Inovação

[...] estabelece medidas de incentivo à inovação e à pesquisa científica e tecnológica no ambiente produtivo, com vistas à capacitação e ao alcance da autonomia tecnológica e ao desenvolvimento industrial do País, nos termos dos artigos 218 e 219 da Constituição. (BRASIL, 2004, art. 19) 
Em seu artigo $2^{\circ}$, IV, Lei n. 10.973 define inovação como "[...] a introdução de novidade ou aperfeiçoamento no ambiente produtivo ou social que resulte em novos produtos, processos ou serviços" (BRASIL, 2004). Esse conceito de inovação foi ampliado pela Lei n. 13.243/2016, que alterou o citado inciso IV do artigo $2^{\circ}$ que passou a ter a seguinte redação:

[...] introdução de novidade ou aperfeiçoamento no ambiente produtivo e social que resulte em novos produtos, serviços ou processos ou que compreenda a agregação de novas funcionalidades ou características a produto, serviço ou processo já existente que possa resultar em melhorias e em efetivo ganho de qualidade ou desempenho. (BRASIL, 2016, art. 2)

A literatura nos traz uma série de definições que ampliam essa definição legal. Um dos primeiros a trabalhar com esse tema, ainda na década de 1980, Drucker (1986) define inovação como a ferramenta usada pelos empreendedores para explorar as mudanças como uma oportunidade para oferecer um novo produto ou serviço. Por outro lado, o autor sustenta que a inovação não precisa ser técnica e nem mesmo ser palpável, sendo que poucas inovações técnicas podem competir, em termos de impacto, com as inovações sociais. Para Schumpeter (1997), as empresas que buscam permanecer inseridas no sistema econômico devem constantemente inovar. Carvalho (2000) ensina que a inovação envolve novos desenvolvimentos situacionais $e$ introdução de ferramentas, artefatos e mecanismos originados do conhecimento pelos quais as pessoas interagem com seu ambiente. O Manual de Oslo (OCDE, 2005, p. 55) define que

[...] uma inovação é a implementação de um produto (bem ou serviço) novo ou significativamente melhorado, ou um processo, ou um novo método de marketing, ou um novo método organizacional nas práticas de negócios, na organização do local de trabalho ou nas relações externas.

Fator essencial para se entender como se efetivam as inovações é que elas devem chegar aos respectivos mercados. Não existe inovação se o produto, processo ou método não for efetivamente introduzido no mercado e propiciar mudança positiva naquele ambiente e algum tipo de retorno para a empresa ou instituição, pública ou privada, envolvida. Paula et al. (2013) afirma que a inovação está relacionada à competitividade no progresso e desenvolvimento de países, refletindo no sucesso e crescimento das empresas e gerando a oferta de novos produtos e serviços. Mansano e Pereira (2016) afirmam que é essencial investir no desenvolvimento de novas tecnologias a fim de contribuir para o desenvolvimento econômico sustentável. Gomes e Teixeira (2018) consideram a inovação como uma espécie de catalisadora para o crescimento econômico da sociedade atual. A inovação mostra-se como mola propulsora para o crescimento da economia tanto de países desenvolvidos como daqueles que pretendem atingir esse patamar.

\subsection{Habitats de Inovação}

Diante da necessidade de se adequar à nova realidade de mercados cada vez mais exigentes, os ambientes organizacionais internos e externos têm de se reconfigurar sob pena de desaparecerem. Novos arranjos institucionais e de redes de organizações estão surgindo nesse novo cenário socioeconômico. Correia e Gomes (2010) destacam a relevância da formação de redes de cooperação e de conhecimento como forma organizacional mais propícia à geração 
e difusão de inovação, visando a agregação dos conhecimentos embutidos nas pessoas e nas organizações. Entre essas novas configurações, as empresas têm buscado criar ambientes cada vez mais voltados à inovação. Esses novos ambientes que envolvem múltiplos atores e funções, interconectados com objetivos comuns relacionados à inovação são chamados de ecossistemas de inovação.

Para Etzkowitz e Leydesdorff (2000), governo, academia e empresa (que formam a Tríplice Hélice) são parte desse ecossistema, que é uma rede de relações em que a informação e talento fluem, por meio de sistemas de criação conjunta de valor sustentado. Os ecossistemas de inovação são formados por indivíduos, empresas e instituições de pesquisa e universidades que, sob programas e leis governamentais, buscam interagir e otimizar a utilização dos recursos $e$ conhecimentos de que cada um dispõe para gerar inovações que cheguem ao mercado gerando não apenas lucro, mas possibilitando a própria sobrevivência das organizações envolvidas. Teixeira et al. (2017) complementam esse conceito apontando que essa comunidade é produtora de bens e serviços de valor para os consumidores que são membros do ecossistema. O número de participantes, suas áreas de atuação e seus papéis em cada ecossistema de inovação variam e suas inter-relações tendem a ser cada vez mais complexas à medida que eles se expandem.

Para Correia e Gomes (2010), como meio de incentivar a geração de inovações as empresas têm criado ambientes que possuem características tecnológicas específicas, chamados de habitats de inovação, cujo objetivo principal é o de favorecer o seu desenvolvimento. Os habitats de inovação são núcleos dentro dos ecossistemas de inovação, e estes ambientes são fundamentais para que os processos de inovação se efetivem. Segundo Teixeira et al. (2017), os habitats de inovação são elementos fundamentais para potencializar o ecossistema de inovação. Nesses habitats se materializam as relações do conceito de Hélice Tríplice, com as universidades e as ICTs atuando em cooperação com as empresas, sob as leis, políticas e programas estabelecidos pelo governo, buscando multiplicar os resultados do conjunto de conhecimentos, estruturas físicas, tecnologias e capital visando ao aumento de ganhos, financeiros ou não, para cada parte envolvida. Luz et al. (2014) afirmam que os habitats de inovação são espaços que promovem o compartilhamento de conhecimentos que podem gerar inovações, buscando a interação entre os atores que participam desse processo, tais como universidades, instituições de pesquisa, empresas e governo.

Para que essas parcerias maximizem seus resultados e estimulem a participação de novos agentes, é fundamental que se busque uma relação do tipo "ganha x ganha", em que todos os envolvidos tenham garantido algum tipo de retorno positivo. Nesse tipo de trabalho conjunto, o objetivo principal é a sinergia no desenvolvimento de tecnologias e a ampliação das possibilidades de negócios. Essas interações, portanto, devem ser pautadas pelo profissionalismo dos atores. Se o resultado desse trabalho conjunto chega ao setor produtivo e provoca mudanças positivas, o processo de inovação estará completo e deverá contribuir para o desenvolvimento econômico. A extensão geográfica dessa contribuição dependerá do tipo de inovação e de sua área de aplicação. Para Teixeira et al. (2017), os habitats de inovação são ambientes que provêm, entre outros, infraestrutura e suporte às empresas, buscando viabilizar seu desenvolvimento por meio de programas específicos voltados à inovação. Como exemplos de habitats de inovação, Pietrovski et al. (2010) citam Hotéis Tecnológicos, Incubadoras, Aceleradoras, Núcleos de Inovação Tecnológica, Centros de Inovação, Polos e Parques Tecnológicos. Teixeira et al. acrescentam 
a esta lista Cidades Intensivas em Conhecimento ou Cidades Inteligentes, Parques (Científicos, de Inovação e os de Pesquisa), Pré-incubadoras, Coworking e Makerspace.

\subsection{Núcleos de Inovação Tecnológica - Conceitos e Aspectos Legais}

Como um dos diversos habitats de inovação, os Núcleos de Inovação Tecnológica (NITs) têm importância fundamental para que os processos de inovação ocorram e as empresas possam prosperar. Os NITs têm a responsabilidade de intermediar e apoiar as transferências de conhecimentos e tecnologias entre as ICTs e universidades e o mercado. Mas esse não é um processo fácil e a realidade das universidades e ICTs brasileiras demonstra que ainda há muito que se fazer para que esse processo seja incorporado adequadamente. Nesse sentido, Ferreira e Teixeira (2018) afirmam que parte da tecnologia desenvolvida nas ICTs não é gerida adequadamente, o que dificulta a incorporação de se seus produtos e processos pelo mercado. As autoras complementam que, se não chegam ao mercado, ocorre apenas uma invenção, não uma inovação.

Esse é um dos grandes desafios para os quais os NITs devem buscar soluções: a transformação dos conhecimentos das universidades e ICTs em inovações. Os NITs devem propor estratégias que estimulem a realização de projetos de desenvolvimento tecnológico e de pesquisa aplicada e sua transferência para o mercado. Segundo Teixeira et al. (2016), os NITs devem gerir a política de inovação da instituição e buscar a interação universidade-empresa. Ehlers e Teixeira (2017) afirmam que os NITs devem viabilizar o diálogo entre as demandas e as ofertas de tecnologias e, assim, devem criar uma ponte entre as universidades, o governo e as empresas em direção à inovação. Para as autoras, as competências conferidas aos NITs pela nova legislação fazem com que eles sejam um importante canal entre as demandas por novas soluções tecnológicas apresentadas pelas empresas e as ICTs, estas detentoras de conhecimentos, resultando na transferência das tecnologias. Dessa forma, as universidades e as ICTs realizam sua função de produzir não só conhecimentos, mas tecnologias que chegam ao mercado e, assim, se concretiza com sucesso o processo de inovação.

A Lei n. 10.973/2004 (Lei de Inovação) conceitua o NIT como "[...] núcleo ou órgão constituído por uma ou mais ICT com a finalidade de gerir sua política de inovação [...]" e traz uma série de normativas relativamente ao tema (BRASIL, 2004, art. $2^{\circ}$ ). A Lei n. 13.243/2016, o Novo Marco Regulatório da Inovação, alterou a referida Lei n. 10.973/2004 e mais nove leis ligadas, direta ou indiretamente, à inovação. Vejamos, a seguir, algumas das alterações importantes trazidas pela Lei n. 13.243/2016 (BRASIL, 2016). No inciso VI do artigo 2º́ há uma nova definição para os NITs: "[...] estrutura instituída por uma ou mais ICTs, com ou sem personalidade jurídica própria, que tenha por finalidade a gestão de política institucional de inovação e por competências mínimas as atribuições previstas nesta Lei" (BRASIL, 2016, art. $2^{\circ}$ ). Ao estabelecer que o NIT pode ter personalidade jurídica própria, a Lei permitiu que a ICT crie seu NIT como um órgão/departamento/setor dentro de sua estrutura funcional, ou que este seja uma entidade desvinculada juridicamente dela, "[...] como entidade privada sem fins lucrativos" (parágrafo $3^{\circ}$ do artigo 16), embora essa desvinculação não seja total, uma vez que o parágrafo $4^{\circ}$ desse mesmo artigo 16 defina que "a ICT deverá estabelecer as diretrizes de gestão e as formas de repasse de recursos". O inciso VI do parágrafo único do artigo 15-A estabelece que a política de inovação da ICT pública "deverá estabelecer diretrizes e objetivos [...] para institucionalização e gestão do Núcleo de Inovação Tecnológica", atrelando a gestão 
do NIT à política da ICT. Já o caput do artigo 16 determina a obrigatoriedade da ICT constituir um NIT quando estabelece que "a ICT deverá dispor de um Núcleo de Inovação Tecnológica" (grifo nosso). Nos dez incisos do parágrafo $1^{\circ}$ desse artigo 16, a Lei define quais são as competências dos NITs.

O Gráfico 1 demonstra os estágios de implantação das atividades obrigatórias desenvolvidas pelos NITs (conforme o estabelecido no artigo 16 da Lei) durante o ano de 2017, elaborado a partir das informações fornecidas pelas próprias ICTs através do preenchimento do Formulário para Informações sobre a Política de Propriedade Intelectual das Instituições Científicas, Tecnológicas e de Inovação do Brasil (FORMICT).

Gráfico 1 - Atividades essenciais dos NITs ordenadas de forma decrescente conforme grau de implementação

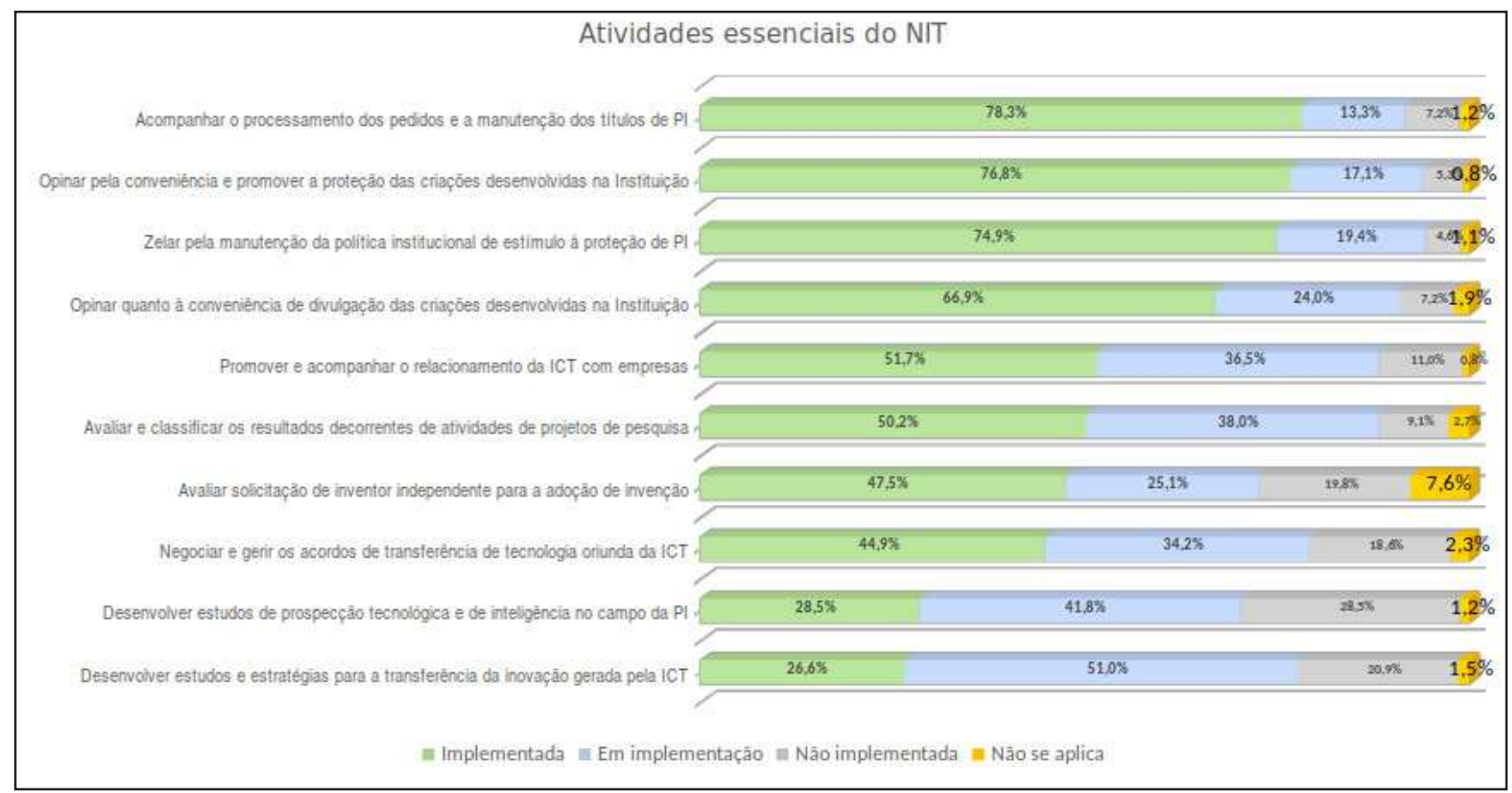

Fonte: Relatório FORMICT 2017 (BRASIL 2019, p. 22)

Os NITs desempenham uma série de atividades fundamentais para a consecução do processo de inovação. Algumas dessas funções são obrigatórias por lei; outras, porém, são definidas pelas próprias políticas das ICTs e universidades para ajustá-las a sua realidade e ao incremento dos resultados de suas atividades de pesquisa e desenvolvimento por meio da inovação.

\section{Metodologia}

A metodologia compreendeu uma revisão de literatura pertinente aos tópicos sobre os quais se discorreu e a avaliação de documentos institucionais físicos e disponíveis no site da Embrapa. 


\section{Resultados e Discussão}

A inovação sempre esteve no DNA da Embrapa. Alves (2010) afirma que a Embrapa é um caso de inovação institucional bem-sucedido e dentre os motivos para esse sucesso estão a escolha do modelo de empresa pública, a descentralização na dimensão territorial e a especialização das Unidades de Pesquisa, a valorização do treinamento e a visão de uma agricultura baseada na ciência e tecnologia.

Desde o início de suas atividades, a Embrapa trabalhou com o objetivo de criar resultados úteis ao agricultor, que viabilizassem sua atividade e possibilitassem seu desenvolvimento econômico. É a teoria da inovação induzida, que segundo Alves (2010) enfatiza a interação dos agricultores com os pesquisadores e destes com a sociedade, estabelecendo-se, assim, as prioridades de pesquisa e evitando-se a dispersão de esforços. Esse foco manteve-se nas quatro décadas de sua existência. De acordo com o VI Plano Diretor da empresa, trabalho em que se buscava antecipar cenários para o período 2014-2034, a Missão da Embrapa é "viabilizar soluções de pesquisa, desenvolvimento e inovação para a sustentabilidade da agricultura, em benefício da sociedade brasileira", e é esta Missão que embasa a Visão estabelecida para a empresa que é "ser referência mundial na geração e oferta de informações, conhecimentos e tecnologias, contribuindo para a inovação e a sustentabilidade da agricultura e a segurança alimentar" (EMBRAPA, 2015, p. 8, grifos nossos).

\subsection{Núcleo de Inovação Tecnológica da Embrapa - NIT Embrapa}

Os NITs somente passaram a ser obrigatórios nas ICTs a partir da promulgação da Lei de Inovação, em 2004. A Embrapa, porém, dadas as características dos resultados de suas atividades e de suas parcerias em Pesquisa, Desenvolvimento e Transferência de Tecnologias, desde a década de 1990 já possuía em sua estrutura áreas responsáveis pela normatização e gestão dos direitos de propriedade intelectual envolvidos. A título exemplificativo dessas normas, podem ser citadas a Deliberação n. 22/1996, que aprovou a Política Institucional de Gestão da Propriedade Intelectual; a Deliberação n. 10/1999, que estabeleceu a Política de Negócios Tecnológicos, e a Deliberação n. 13/2000, que estabeleceu as normas gerais para recebimento e transferência de materiais biológicos.

Pela complexidade dos temas tratados e da relevância dos mesmos para a empresa, essas áreas têm passado por muitas reestruturações. Em 1998, foi criada a Secretaria de Propriedade Intelectual (SPRI); em 1999, os Escritórios de Negócios Tecnológicos; em 2003, a SPRI foi transformada em Gerência Adjunta de Propriedade Intelectual (GPI); e, em 2006, a Diretoria iniciou articulação para constituição de um Núcleo de Inovação Tecnológica na Embrapa (NIT Embrapa). Nas propostas iniciais, o NIT Embrapa foi planejado como uma Unidade de assessoramento a toda a empresa, tendo como responsabilidades básicas a articulação de parcerias e de ações institucionais com objetivo de potencializar a produção científica e tecnológica em suas unidades de pesquisa. O foco principal do NIT Embrapa seria a geração, a adaptação e a transferência de tecnologias inovadoras.

Embora o Parágrafo $1^{\circ}$ do artigo 16 da Lei de Inovação listasse 10 competências básicas para os NITs, nas primeiras estruturas na Embrapa que se assemelhavam a um NIT havia mais do que o dobro destas atribuições, pois as áreas afetas à inovação, negócios e propriedade in- 
telectual tinham em sua responsabilidade atribuições como o assessoramento direto ao Diretor-Presidente e a todas as Unidades nas questões concernentes à gestão da inovação tecnológica; a emissão de parecer sobre matérias jurídicas especificamente relacionadas à Lei de Inovação $e$ às legislações relacionadas à proteção intelectual, biossegurança, acesso a recursos genéticos e matérias conexas; treinamento dos empregados visando à qualificação técnica nos assuntos pertinentes à inovação tecnológica, inteligência competitiva, gestão de negócios e empreendedorismo; identificação de oportunidades de negócios buscando parcerias para a inovação; elaboração do portfólio de tecnologias existentes visualizando o mercado atual e potencial; análise de proteção legal, potenciais parceiros, viabilidade econômica, risco e potencial de geração de impactos da inovação, na concepção e execução de projetos; desenvolvimento de metodologias para valoração de tecnologias, serviços, processos e conhecimentos inovadores e implantação de planos de negócios para a disponibilização e comercialização de tecnologias ao mercado.

A Embrapa continuou a fazer ajustes em sua estrutura responsável pela gestão da Inovação e da Propriedade Intelectual. Em 2007, a GPI foi transformada em Assessoria de Inovação Tecnológica (AIT), que incorporou, dentre outras, as funções de um NIT. Em 2012, foi criada a Secretaria de Negócios (SNE), que absorveu as funções do Departamento de Negócios Tecnológicos, da Gerência de Planejamento e Negócios e da Assessoria de Inovação Tecnológica. A SNE estava subordinada diretamente ao Diretor-Presidente da Embrapa, demonstrando a importância que a empresa lhe atribuía. Em 2017, a SNE foi transformada em Secretaria de Inovação e Negócios (SIN), ligada diretamente à nova diretoria criada, a Diretoria Executiva de Inovação e Tecnologia (DE-IT). Essa mudança, principalmente a transição do que era anteriormente uma Diretoria de Transferência de Tecnologia e passou a ser a nova Diretoria de Inovação e Tecnologia, implicou não apenas em uma alteração de nomenclatura, mas no fortalecimento dos processos de inovação e negócios da empresa. O objetivo da criação da DE-IT foi ampliar o tradicional conceito de transferência de tecnologia para a constituição de relações mais consistentes com os produtores rurais e com o mundo dos negócios e tecnologia. Por sua vez, a SIN ampliou sua atuação incorporando as funções da Embrapa Produtos e Mercados, do Departamento de Transferência de Tecnologia e da Embrapa Informação Tecnológica, além de outras funções realizadas pelas demais Unidades Centrais relacionadas à inovação e negócios.

A SIN foi criada como uma unidade organizacional do nível tático, vinculada à DE-IT, sendo corresponsável pela gestão do Macroprocesso de Inovação e responsável pelos processos de gestão de ativos, gestão de inovação e negócios, gestão de marketing e gestão do escalonamento e exploração comercial de ativos, bem como a coordenação da rede de inovação e negócios da Embrapa. Conforme seu regimento, publicado pela primeira vez em $1^{\circ}$ de fevereiro de 2018 (EMBRAPA, 2018a), a SIN configura-se explicitamente como o Núcleo de Inovação Tecnológica (NIT) da Embrapa, conforme previsto no artigo 16 da Lei n. 10.973/2004, assumindo todas as competências estabelecidas no referido artigo e aquelas que venham a ser definidas no seu Regulamento e na Política de Inovação da Embrapa. Um dos grandes avanços da nova estrutura é que a SIN passou a ter um corpo jurídico dedicado, o que permite maior celeridade e análises mais especializadas quanto aos temas ligados à inovação e aos negócios.

Nessa esteira, um dos marcos na renovação estrutural e estratégica da Embrapa para a inovação foi a publicação de sua Política de Inovação (EMBRAPA, 2019c), documento pioneiro por já incorporar as várias possibilidades trazidas pelo Novo Marco Legal de Ciência, Tecnologia e Inovação e pelo seu Regulamento. 
O NIT da Embrapa segue capitaneando ações, incorporando e estabelecendo normativos internos à Embrapa que permitam tornar a atuação da empresa no mercado de inovações cada vez mais dinâmica, efetiva e desburocratizada.

\subsection{O Macroprocesso de Inovação da Embrapa}

Entre as mudanças recentemente implantadas, ou que estão em fase de implementação na empresa, está o projeto de alteração do modelo de gestão da instituição, do tradicional Macroprocesso de Produção, direcionado à produção de produtos e serviços, para o Macroprocesso de Inovação, um modelo diretamente ligado à entrega de resultados para a sociedade. Esse processo foi iniciado pela Secretaria de Negócios, em 2012, e retomado em 2017, quando a empresa intensificou o processo de avaliação sobre como as suas ações, definidas por meio dos projetos de pesquisa, estavam voltadas (ou não) ao alcance da missão de viabilizar soluções de PD\&I para a agricultura e a sociedade. A empresa buscava, assim, aprimorar o processo de transformação de sua produção científica em tecnologias aplicadas aos sistemas produtivos. Um dos primeiros resultados desse trabalho foi o estabelecimento de um novo modelo conceitual de inovação, conforme a Figura 1.

Figura 1 - Modelo de Inovação da Embrapa

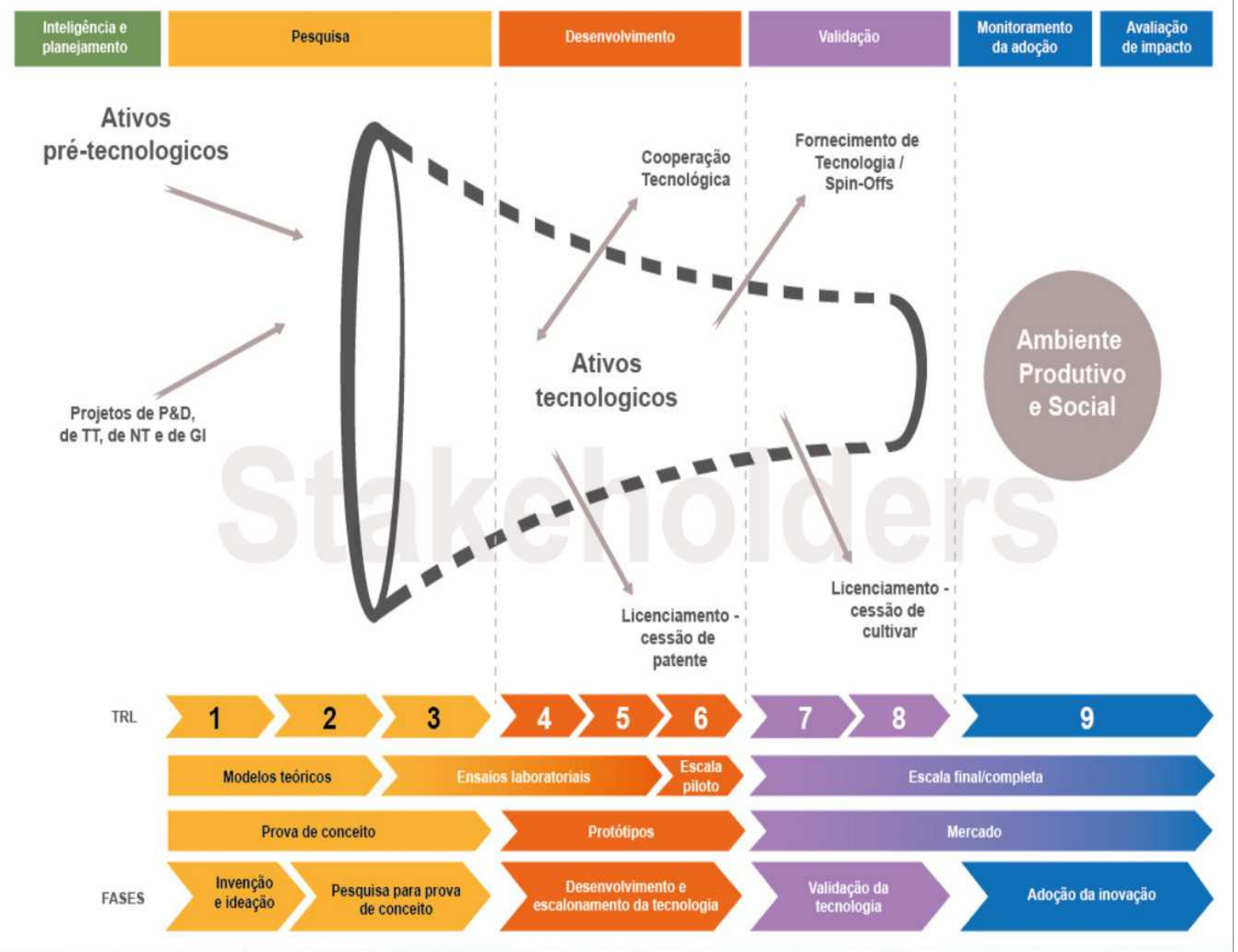

Fonte: Embrapa (2019d) 
O Modelo de Inovação Embrapa tem como enfoque a inovação aberta e, como tal, sua premissa básica são as parcerias com instituições públicas e privadas ligadas ao setor produtivo e que terão funções e importância em todo o processo, desde a proposição dos projetos de pesquisa e desenvolvimento até a inserção dos ativos gerados no mercado, possibilitando a otimização da utilização dos recursos das instituições e empresas. Discorrendo sobre as vantagens da inovação aberta, Chesbrough (2003) ensina que as empresas devem lucrar com todos os usos possíveis de propriedade intelectual, sejam elas originariamente suas ou negociadas com terceiros, abrindo-se às parcerias a fim de alavancar seu modelo de negócio e aproveitar as competências e recursos externos de forma sinérgica.

Outras das premissas para a elaboração do Macroprocesso de Inovação da Embrapa foram o estabelecimento de um modelo de referência para as Unidades Centrais e Descentralizadas, objetivando a unificação da linguagem; fortalecimento da inovação aberta; utilização da escala Technology Readiness Level (TRL) (Nível de Prontidão Tecnológica) como referência para o desenvolvimento de soluções tecnológicas; entrega de um número maior de inovações a partir dos avanços do conhecimento; implementação de estruturas de monitoramento do macroprocesso; adoção da abordagem stage-gates e, por fim, retroalimentação dos processos com as informações geradas. Dentre as expectativas com o Macroprocesso estão a promoção da eficácia (produzir melhores resultados), eficiência (eliminar redundâncias) e a efetividade (gerar maiores impactos econômicos) organizacional e estruturar suas ações em processos que ampliem os resultados e diminuam a burocracia, esta considerada um dos maiores entraves para a agilidade da empresa (EMBRAPA, 2018b).

A Figura 2 demonstra o modelo conceitual do Macroprocesso de Inovação da Embrapa.

Figura 2 - Modelo conceitual do Macroprocesso de Inovação da Embrapa

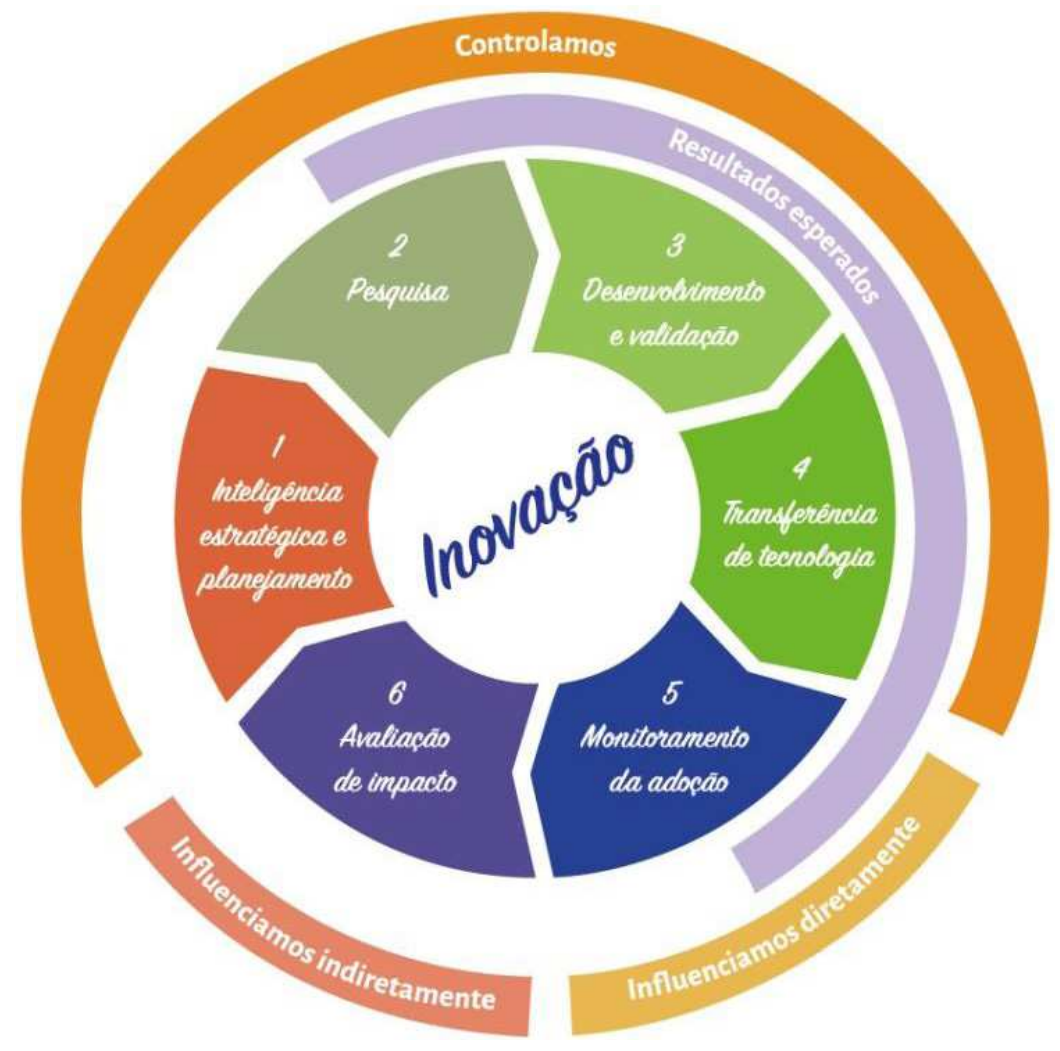

Fonte: Embrapa (2018b) 
O Macroprocesso de Inovação da Embrapa foi estruturado, portanto, em seis etapas (EMBRAPA, 2018b):

Etapa 1: Inteligência Estratégica e Planejamento. Nessa etapa, ocorre o direcionamento estratégico da empresa, sendo geradas informações para as demais etapas e tomadas decisões sobre quais serão os problemas ou oportunidades a serem enfrentados pela empresa visando a entregar valor para a sociedade brasileira. Quatro grandes processos compõem essa etapa: Prospecção, Macroestratégia, Planejamento Corporativo e Planejamento das Unidades (Centrais e/ou Descentralizadas de Pesquisa).

Etapa 2: Pesquisa. A etapa de Pesquisa é realizada quando o planejamento do Centro de Pesquisa, definido na Etapa 1, prevê a entrega de ativos pré-tecnológicos e tecnológicos até o nível 3 da escala TRL (prova de conceito). Existe uma ligação entre a etapa de Pesquisa e a etapa de Desenvolvimento e Validação, fazendo com que o fluxo siga no caso de entrega de ativos na TRL 4. Dentre os processos que são executados em paralelo durante esta etapa estão a estruturação de parcerias, compliance de assuntos regulatórios e a qualificação de ativos. O processo de qualificação foi reestruturado de forma a acompanhar todo o processo de geração, desenvolvimento e validação de ativos a fim de cadastrar e qualificar os produtos, processos, serviços e ativos de base tecnológica desenvolvidos para sua transferência ao mercado. Esse processo é operacionalizado por meio do Sistema de Gestão das Soluções Tecnológicas da Embrapa (GESTEC), uma plataforma digital alimentada por empregados (chamados de Pontos Focais) de cada uma das Unidades de Pesquisa.

Etapa 3: Desenvolvimento e Validação. Fazem parte dessa etapa do Macroprocesso os seguintes estágios de desenvolvimento tecnológico: otimização, prototipagem, escalonamento, demonstração em ambiente de produção e produção. O estágio 9 da TRL/MRL, porém, que diz respeito à produção continuada de tecnologias em sua forma final, não faz parte do modelo de negócio da Embrapa, uma vez que ela não tem estrutura para tal. Assim, a escala industrial das tecnologias desenvolvidas pela empresa é realizada por firmas da iniciativa privada a partir da celebração de contratos de parceria, de licenciamento ou de cessão. O Desenvolvimento e Validação de uma solução tecnológica devem ser planejados na Agenda de Prioridades das Unidades de Pesquisa como uma Meta para Inovação Tecnológica (MIT). Essa MIT, por sua vez, contribui para superar os Desafios de Inovação estabelecidos nos Projetos de Pesquisa.

Etapa 4: Transferência de Tecnologia (TT). Essa etapa é executada quando a Embrapa já tem uma tecnologia pronta para solucionar um problema detectado ou para aproveitar uma oportunidade percebida no mercado; quando as etapas de Pesquisa e/ou Desenvolvimento e Validação chegaram a um conhecimento que deve ser disponibilizado; ou, ainda, quando estas duas etapas precisam de prospecção e formalização de parcerias com novos parceiros ou com aqueles que já desenvolvem trabalhos conjuntos. Verifica-se, portanto, que a Transferência de Tecnologia pode ser executada depois ou mesmo durante as etapas de Pesquisa e Desenvolvimento e Validação. O foco da etapa de TT é aproximar as tecnologias e conhecimentos desenvolvidos pela Embrapa, sozinha ou em conjunto com seus parceiros, de potenciais clientes para que o processo de inovação seja completado com sucesso. Buscam-se, prioritariamente, parceiros empenhados em fazer com que os ativos cheguem ao mercado. Nesta etapa, alguns processos são executados, como o Plano de Marketing, peça fundamental em que são detalhadas as ações necessárias para se atingir os objetivos; Gestão de Riscos; Gestão da Propriedade Intelectual; Estruturação de Parcerias e Formação de Redes, e Captação de Recursos. 
Etapa 5: Monitoramento da Adoção de Ativos. Nesta etapa estão previstos os processos de Planejamento, Execução e Avaliação dos Resultados obtidos a partir do Monitoramento da Adoção dos Ativos. Prevê-se, ainda, nesta etapa, a Avaliação do Desempenho Técnico dos ativos da Embrapa durante todo o tempo em que os mesmos permanecerem no mercado, gerando informações para a etapa de Avaliação de Impactos e retroalimentando as etapas de Transferência de Tecnologia e de Inteligência Estratégica e Planejamento.

Etapa 6: Avaliação de Impactos. Nesta etapa pretende-se medir de forma qualificada o benefício econômico, social e/ou ambiental de suas soluções tecnológicas para a sociedade, subsidiando a empresa na tomada de decisões para ações futuras. Essa etapa envolve a seleção amostral dos ativos a serem avaliados, a avaliação de seus impactos e, por fim, a divulgação dos resultados obtidos. Assim, nesta etapa podem ser definidas mudanças nos processos adotados ou até mesmo a retirada da tecnologia do mercado. Os impactos dos ativos retroalimentam o Macroprocesso de Inovação e os processos internos e externos de prestação de contas da empresa.

\section{Considerações Finais}

A Embrapa foi uma empresa criada com o objetivo de desenvolver uma agricultura forte para o país a fim de atender ao mercado interno e fortalecer as exportações. Dessa forma, pretendia-se não apenas equilibrar a balança comercial nacional, mas positivá-la e proporcionar seu crescimento contínuo. Para isso, a agricultura brasileira precisaria dar um salto de qualidade e produtividade. Perseguindo esse objetivo, a Embrapa tornou-se um grande habitat de inovação, capitaneado pelas estratégias definidas pela alta direção da empresa, assessorada pelas diversas configurações que o NIT Embrapa teve ao longo da história, mesmo quando ainda não tinha esse nome, e executada por um corpo técnico altamente qualificado e comprometido, tornando-se a grande indutora do desenvolvimento da agricultura nacional.

Buscando resultados objetivos sobre esses avanços, tem-se, por exemplo, o período de 2002 a 2017, que demonstra parte do que aconteceu com a agricultura brasileira. O saldo da balança comercial do agronegócio nesse período saltou de pouco mais de US $\$ 20$ bilhões para quase US\$ 82 bilhões, um aumento de 300\%. Em 2018, as exportações do agronegócio foram da ordem de US\$ 101 bilhões. O Brasil é hoje o maior exportador mundial de café, açúcar, suco de laranja, etanol de cana-de-açúcar, frango, carne bovina e soja. Sozinho, o complexo soja foi responsável por cerca de $29 \%$ de todas as vendas externas do agronegócio em 2018. O Setor Agropecuário contribui com $22,5 \%$ do PIB nacional e $37 \%$ da força de trabalho. As exportações brasileiras saltaram de US \$13,9 bilhões em 1989 para US\$101,6 bilhões em 2018 (EMBRAPA, 2018c).

Se, por um lado, seria um desatino creditar todos esses números à Embrapa, por outro não há como negar sua contribuição efetiva para que esses resultados fossem possíveis. Os processos sob gestão no NIT Embrapa comprovam isso: Patentes no Brasil: 413; Patentes no Exterior: 428; Solicitação de Proteção de Cultivares no Brasil: 723; Solicitação de Proteção de Cultivares no exterior: 15; Solicitação de Registro Comercial de Cultivares: 1.701; Registro de Softwares: 123; Registro de Marcas: 432 (EMBRAPA, 2018c).

Todo o trabalho da empresa tem criado soluções que são entregues aos agricultores sob a forma de produtos, protótipos, sistemas e softwares; as inovações tecnológicas. Por outro lado, 
grande parte dos esforços da empresa chega ao agricultor sob a forma de serviços, metodologias, processos e práticas agropecuárias, as inovações sociais. Para cumprir sua missão e viabilizar o crescimento da agropecuária brasileira, a empresa tem feito constantes ajustes institucionais para aprimorar suas ações e ampliar seus resultados de pesquisa, desenvolvimento e inovação. A criação e as iniciativas que remontam o ano de 2006, já precursoras do que seria chamado de NIT Embrapa, e o fortalecimento de suas atribuições ao longo dos anos demonstram a importância que a empresa atribui ao tema e o amadurecimento já alcançado.

Complementarmente, o Macroprocesso de Inovação demonstra claramente que a Embrapa está focada em fortalecer o processo de inovação e, assim, continuar a participar do desenvolvimento econômico e social do país, entregando resultados cada vez mais relevantes para o Brasil e consolidando-se no cenário da pesquisa agropecuária internacional como a principal referência do mundo tropical.

\section{Referências}

ALVES, E. Embrapa: um caso bem-sucedido de inovação institucional. Revista de Política Agrícola, Brasília, DF, ano 19, p. 65-73, jul. 2010. Edição especial. Disponível em: https://ainfo. cnptia.embrapa.br/digital/bitstream/item/80777/1/Embrapa-um-caso-bem-sucedido.pdf. Acesso em: 31 maio 2019.

BRASIL. [Constituição de 1988]. Constituição da República Federativa do Brasil. Brasília, DF: Presidência da República, [2016]. Disponível em: http://www.planalto.gov.br/ccivil_03/constituicao/ constituicao.htm. Acesso em: 22 jul. 2019.

BRASIL. Emenda Constitucional n. 85, de 26 de fevereiro de 2015. Altera e adiciona dispositivos na Constituição Federal para atualizar o tratamento das atividades de ciência, tecnologia e inovação. Disponível em: http://www.planalto.gov.br/ccivil_03/constituicao/Emendas/Emc/emc85. htm. Acesso em: 21 jul. 2019.

BRASIL. Lei n. 9.279, de 14 de maio de 1996. Regula direitos e obrigações relativos à propriedade industrial. Disponível em: http://www.planalto.gov.br/ccivil_03/Leis/L9279.htm . Acesso em: 25 mar. 2019.

BRASIL. Lei n. 9.456, de 25 de abril de 1997. Institui a Lei de Proteção de Cultivares e dá outras providências. Disponível em: http://www.planalto.gov.br/ccivil_03/LEIS/L9456.htm. Acesso em: 20 jul. 2019.

BRASIL. Lei n. 9.609, de 19 de fevereiro de 1998. Dispõe sobre a proteção da propriedade intelectual de programa de computador, sua comercialização no País, e dá outras providências. Disponível em: http://www.planalto.gov.br/ccivil_03/leis/19609.htm. Acesso em: 20 jul. 2019.

BRASIL. Lei n. 9.610, de 19 de fevereiro de 1998. Altera, atualiza e consolida a legislação sobre direitos autorais e dá outras providências. Disponível em: http://www.planalto.gov.br/ccivil_03/leis/ 19610.htm. Acesso em: 20 jul. 2019.

BRASIL. Lei n. 10.973, de 2 de dezembro de 2004. Dispõe sobre incentivos à inovação e à pesquisa científica e tecnológica no ambiente produtivo e dá outras providências. Disponível em: http://www.planalto.gov.br/ccivil_03/_ato2004-2006/2004/lei/110.973.htm. Acesso em: 26 jul. 2019.

BRASIL. Lei n. 13.123, de 20 de maio de 2015. Regulamenta o inciso II do $\S 1^{\circ}$ e o $\S 4^{\circ}$ do art. 
225 da Constituição Federal, o Artigo 1, a alínea j do Artigo 8, a alínea c do Artigo 10, o Artigo 15 e os $\S \S 3^{\circ}$ e $4^{\circ}$ do Artigo 16 da Convenção sobre Diversidade Biológica, promulgada pelo Decreto $\mathrm{n}^{\circ}$ 2.519, de 16 de março de 1998; dispõe sobre o acesso ao patrimônio genético, sobre a proteção e o acesso ao conhecimento tradicional associado e sobre a repartição de benefícios para conservação e uso sustentável da biodiversidade; revoga a Medida Provisória n ${ }^{\circ}$ 2.186-16, de 23 de agosto de 2001; e dá outras providências. Disponível em: http://www.planalto.gov.br/ccivil_03/_ato20152018/2015/lei/113123.htm. Acesso em: 21 jul. 2019.

BRASIL. Lei n. 13.243, de 11 de janeiro de 2016. Dispõe sobre estímulos ao desenvolvimento científico, à pesquisa, à capacitação científica e tecnológica e à inovação e altera a Lei n. 10.973, de 2 de dezembro de 2004, a Lei n. 6.815, de 19 de agosto de 1980, a Lei n. 8.666, de 21 de junho de 1993, a Lei n 12.462 , de 4 de agosto de 2011, a Lei n ${ }^{\circ} 8.745$, de 9 de dezembro de 1993, a Lei n. 8.958, de 20 de dezembro de 1994, a Lei n. 8.010, de 29 de março de 1990, a Lei n. 8.032, de 12 de abril de 1990, e a Lei n. 12.772, de 28 de dezembro de 2012, nos termos da Emenda Constitucional n. 85, de 26 de fevereiro de 2015. Disponível em: http://www.planalto.gov. br/ccivil_03/_Ato2015-2018/2016/Lei/L13243.htm. Acesso em: 26 jul. 2019.

BRASIL. Ministério da Ciência, Tecnologia, Inovações e Comunicações. Secretaria de Empreendedorismo e Inovação. Política de propriedade intelectual das instituições científicas, tecnológicas e de inovação do Brasil: relatório FORMICT 2017. Brasília, DF, 2019. 59 p. Disponível em: https:/www.mctic.gov.br/mctic/export/sites/institucional/tecnologia/propriedade_ intelectual/arquivos/Relatorio-Consolidado-Ano-Base-2017.pdf. Acesso em: 16 jul. 2019.

CARVALHO, F. C. A. Gestão do conhecimento: o caso de uma empresa de alta tecnologia. 2000. 115 f. Dissertação (Mestrado em Engenharia de Produção) - Universidade Federal de Santa Catarina, Florianópolis, 2000. Disponível em: https://repositorio.ufsc.br/xmlui/bitstream/ handle/123456789/78363/153139.pdf?sequence=1\&isAllowed=y. Acesso em: 31 jul. 2019.

CHESBROUGH, H. W. Open innovation: the new imperative for creating and profiting from technology. Harvard Business School Press, Boston, 2003. 272 p.

CORREIA, A. M. M.; GOMES, M. L. B. Habitat de inovação PAQTCPB: identificando ações de sucesso. Gestão \& Sociedade Revista Eletrônica, Belo Horizonte, v. 4, n. 8, p. 591-618, maio/ ago. 2010. Disponível em: https://www.gestaoesociedade.org/gestaoesociedade/article/view/897/814. Acesso em: 22 abr. 2019.

DRUCKER, P. Inovação e espírito empreendedor (Entrepreneurship): prática e princípios. São Paulo: Thomson Pioneira, 1986. 378 p.

EHLERS, A. C. S. T.; TEIXEIRA, C. S. Pontes entre a tríplice hélice e a inovação. Revista Via, Florianópolis, ano 2, n. 3, p. 5-7, dez. 2017. Disponível em: http://via.ufsc.br/wp-content/ uploads/2017/12/revistaVIA-3ed.pdf. Acesso em: 21 jun. 2019.

EMBRAPA. Aprova a Norma n. 037.005.001.012, intitulada "Política de Inovação da Embrapa", integrante do Manual de Normas da Embrapa. Resolução do CONSAD n. 179, de 17 dez. 2018. 2019c. Boletim de Comunicações Administrativas, Brasília, DF, ano 45, n. 2, p. 6, jan. 2019.

EMBRAPA. Deliberação n. 1, de 30 jan. 2018. Aprova o Regimento que estabelece as finalidades, a estrutura organizacional, as competências e as atribuições das Secretarias da Embrapa. Boletim de Comunicações Administrativas, Brasília, DF, ano 44, n. 8, p. 6-7, fev. 2018a.

EMBRAPA. Embrapa chega aos 46 anos pronta para novos desafios. 2019a. Disponível em: https:/www.embrapa.br/busca-de-noticias/-/noticia/42742148/embrapa-chega-aos-46-anos-prontapara-novos-desafios. Acesso em: $1^{\circ}$ ago. 2019. 
EMBRAPA. Inovação está no DNA da Embrapa: a gente faz ciência que transforma. 2019d. Disponível em: https://www.embrapa.br/group/intranet/macroprocesso-de-inovacao/. Acesso em: 2 jul. 2019.

EMBRAPA. Secretaria de Desenvolvimento Institucional. Balanço Social 2018. Brasília, DF, 2019b. 61 p. Disponível em: https://bs.sede.embrapa.br/2018/balsoc18.html. Acesso em: 23 jul. 2019.

EMBRAPA. Secretaria de Desenvolvimento Institucional. Macroprocesso de Inovação da Embrapa. Documento Orientador. Brasília, DF: SDI; SPD; SIN, 2018. 10 p.

EMBRAPA. Secretaria de Gestão e Desenvolvimento Institucional. VI Plano Diretor da Embrapa 2014-2034. Brasília, DF, 2015. 24 p. Disponível em: http://ainfo.cnptia.embrapa.br/digital/bitstream/ item/130562/1/Plano-Diretor-da-Embrapa-2014-2034.pdf. Acesso em: 28 abr. 2019.

EMBRAPA. Secretaria Geral. Gerência de Comunicação. Embrapa em números. Brasília, DF, 2018c. 134 p. Disponível em: https://www.embrapa.br/documents/10180/1600893/

Embrapa $+e m+N \% C 3 \% B A m e r o s / 7624614 b-f f 8 c-40 c 0-a 87 f-c 9 f 00 c d 0 a 832$. Acesso em: 31 ago. 2019.

ETZKOWITZ, H.; LEYDESDORFF, L. The dynamics of innovation: from national systems and "Mode 2" to a Triple Helix of university-industry-government relations. Research Policy, [S.I.], v. 29, n. 2, p. 109-123, feb. 2000. Disponível em: https://www.researchgate.net/publication/222547985_The_ Dynamics_of_Innovation_From_National_Systems_and_Mode_2_to_a_Triple_Helix_of_University-

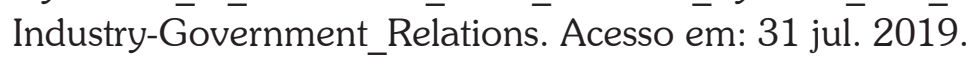

FERREIRA, M. C. Z.; TEIXEIRA, C. S. Os Núcleos de Inovação Tecnológica no Brasil. In: DEPINÉ, A.; TEIXEIRA, C. S. (org.). Habitats de Inovação: conceito e prática. São Paulo: Perse, 2018. p. 151-176. Disponível em: http://via.ufsc.br/wp-content/uploads/2018/05/HABITATS-DE-INOVACAOconceito-e-pratica.pdf. Acesso em: 31 ago. 2019.

GOMES, R. A. O. S.; TEIXEIRA, C. S. As tipologias de habitats de inovação: uma análise da legislação vigente do sul do Brasil sob luz do novo marco legal de ciência, tecnologia e inovação.

Revista Eletrônica do Alto do Vale do Itajaí - REAVI, Itajaí, v. 7, n. 11, p. 1-9, dez. 2018. Disponível em: http://via.ufsc.br/wp-content/uploads/2018/12/14312-49109-1-PB.pdf. Acesso em: 27 abr. 2019.

LUZ, A. A. et al. Habitats de inovação e a sinergia do potencial acadêmico, tecnológico e inventivo em Ponta Grossa, Paraná, Brasil. Revista Espacios, Caracas, v. 35, n. 6, p. 1-15, 2014. Disponível em: https:/www.revistaespacios.com/a14v35n06/14350601.html. Acesso em: 12 jun. 2019.

MANSANO, F. H.; PEREIRA, M. F. Business incubators as support mechanisms for the economic development: case of Maringá's Technology Incubator. International Journal of Innovation Journal, São Paulo, SP, v. 4, n. 1, p. 23-32, jan./jun. 2016. Disponível em: http://www.journaliji.org/ index.php/iji/article/view/51. Acesso em: 28 abr. 2019.

OCDE - ORGANIZAÇÃO PARA A COOPERAÇÃO E DESENVOLVIMENTO ECONÔMICO. Manual de Oslo: diretrizes para coleta e interpretação de dados sobre inovação. 3. ed. Paris: OCDE, 2005. 184 p.

PAULA, R. M. et al. Aplicação do modelo hélice tríplice para incentivar o processo de inovação: a experiência da empresa Prática Produtos S/A. In: CONGRESSO LATINO-IBEROAMERICANO DE GESTÃO TECNOLÓGICA, 15., 2013, Cartagena. Novas condições e espaços para o desenvolvimento científico, tecnológico e industrial e a cooperação internacional: anais. Cartagena: ALTEC, 2013. 13 p. Disponível em: http://www.altec2013.org/programme_pdf/1236.pdf. Acesso em: 30 abr. 2019. 
PIETROVSKI, E. F. et al. Habitats de inovação tecnológica. In: Congresso de Pesquisa e Inovação da Rede Norte Nordeste de Educação Tecnológica. 5. 2010. Maceió. Anais [...] Maceió: 2010. Disponível em: http://connepi.ifal.edu.br/ocs/anais/. Acesso em: 15 jun. 2019.

SANTOS, D. A. Cooperação tecnológica universidade-empresa-governo: um estudo de casos múltiplos da Universidade Federal de Sergipe. 2011. 161 f. Dissertação (Mestrado em Desenvolvimento Regional e Gestão de Empreendimentos Locais) - Universidade Federal de Sergipe, São Cristóvão, 2011. Disponível em: https://ri.ufs.br/bitstream/riufs/4530/1/DANIELLE_ ANDRADE_SANTOS.pdf. Acesso em: 15 jun. 2019.

SCHUMPETER, J. A. Teoria do desenvolvimento econômico. São Paulo: Nova Cultural, 1997. $239 \mathrm{p}$.

TEIXEIRA, C. S. et al. Habitats de inovação: alinhamento conceitual. Florianópolis: Perse, 2016. 10 p. E-book. Disponível em: https://correio.embrapa.br/service/home/ /xE-book_Habitats\%20 de\%20inovacao\%20-\%20alinhamento\%20conc.pdf?auth $=$ co\&loc $=$ pt_BR\&id $=102131 \&$ part $=2$. Acesso em: 24 jul. 2019.

TEIXEIRA, C. S. et al. Ecossistema de inovação: alinhamento conceitual. Florianópolis: Perse. 24 p. 2017. E-book. Disponível em: http://via.ufsc.br/wp-content/uploads/2017/07/e-bookEcossistemadeinovacao.pdf. Acesso em: 20 maio 2019.

\section{Sobre os Autores}

\section{Luís Carlos Stutz}

E-mail: luis.stutz@embrapa.br

Analista no Setor de Prospecção e Avaliação de Tecnologias da Embrapa Soja e Aluno do Programa de PósGraduação - Mestrado em Propriedade Intelectual e Transferência de Tecnologia para a Inovação (PROFNIT) Polo UEM.

Endereço profissional: Rodovia Carlos João Strass, Distrito de Warta, PR. CEP: 86001-970.

\section{Marcelo Farid Pereira}

E-mail: faridmarcelo@gmail.com

Professor nas áreas de Análise de Investimentos e Habitats de Inovação da UEM e do Programa de Pós-Graduação - Mestrado em Propriedade Intelectual e Transferência de Tecnologia para a Inovação (PROFNIT), Polo UEM. Endereço profissional: Rua Jair do Couto Costa, 657-769, Conj. Hab. Inocente, Vila Nova Júnior, Maringá, PR. CEP: 87060-625. 